\title{
On the Birthday of Svetlana Viktorovna Kurbatova
}

DOI: $10.1134 / \mathrm{S} 1061934811060220$

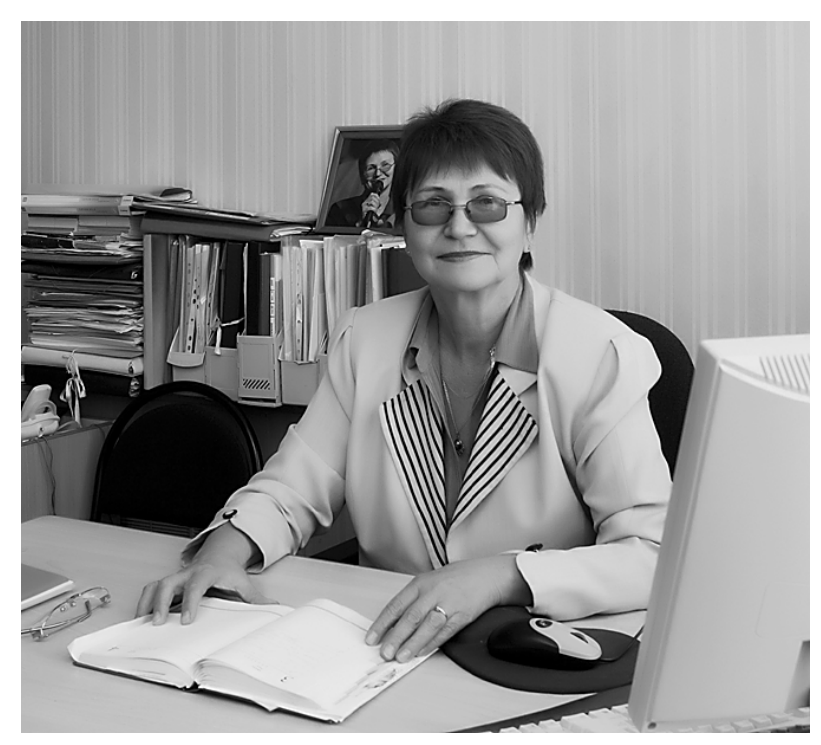

January 30, 2011 was the birthday of Svetlana Viktorovna Kurbatova, Doctor of Chemistry, Professor of the Division of Physical Chemistry and Chromatography, and Dean of the Chemical Faculty of Samara State University. Professor Kurbatova graduated from the Chemistry Faculty of Saratov State University in 1973 and from that time has worked at Samara (Kuibyshev prior to 1980) State University. She passed through all the levels of teaching positions, from assistant professor to professor. In 1991 she defended her candidate's dissertation and in 2000, her doctoral dissertation. She has been the Dean of the Chemistry Faculty since 1997.

The scientific works of Professor Kurbatova are devoted to the physicochemical basis of separation processes, especially the chromatography and physical chemistry of adamantine derivatives and aromatic heterocycles. The main results of her studies were described in the monograph Khromatografiya proizvodnykh adamantana (Chromatography of Adamantane Derivatives). Professor Kurbatova is the author or coauthor of more than 200 scientific publications, study guides, and student textbooks. She has made many presentations at international and all-Russia conferences on chemical thermodynamics, adsorption, and chromatography; as well as presenting at Mendeleev Congresses and sessions of the Scientific Council on Adsorption and Chromatography of the Russian Academy of Sciences.

She is actively engaged in teaching and organizational work. As well, she delivers lecture courses on physical chemistry, biophysical and medical chemistry, physicochemical research methods, physicochemical basics of medical diagnosis, and other subjects to bachelors, specialists, and masters students. Professor Kurbatova supervises graduate students, masters, and diploma students; 11 candidate's dissertations have been defended under her supervision.

She is a member of the dissertation council at Samara State University, of the Presidium of the Chemistry Council of the Education and Methodics Association on Classical University Education, the International QSAR and Modeling Society, and the editorial boards of the journals Vestnik Samarskogo Gosudarstvennogo Universiteta and Butlerovskie Soobshcheniya. She has worked constantly on the organizing committees of scientific conferences at various levels.

Professor Kurbatova has also participated in the organization of new specialties at the Chemistry Faculty, viz., specialties in medical chemistry, petrochemistry, environmental chemistry, chemical technique, and environmental safety. She is also engaged in the teaching of two master's courses in physical chemistry and organic chemistry.

Svetlana Viktorovna was awarded an honorary certificate from the Mayor of Samara, the "For Service to the City" medal, and an honorary certificate from the Ministry of Education and Science of the Russian Federation.

Her colleagues and friends congratulate Svetlana Viktorovna on her birthday and wish her good health; major success in her scientific, pedagogical, and organizational work; and good students. 